\title{
FARELO DE ARROZ: CARACTERÍSTICAS, BENEFÍCIOS À SAÚDE E APLICAÇÕES
}

VANESSA RIBEIRO PESTANA*

CARLA R.B. MENDONÇA**

RUI CARLOS ZAMBIAZI**

\begin{abstract}
Neste trabalho de revisão de literatura, a composição, a estabilidade, as aplicações e os benefícios à saúde do farelo de arroz foram abordados. Aspectos referentes à composição de biofenóis no óleo de arroz e novas tecnologias empregadas para extração e refino do óleo também foram discutidos. Subproduto do beneficiamento do arroz com amplas possibilidades de uso, o farelo evidencia grande potencial econômico. O consumo humano de farelo e óleo de arroz no Brasil ainda é reduzido, no entanto, a tendência do mercado mundial e as pesquisas apontam para promissoras aplicações desse produto.
\end{abstract}

PALAVRAS-CHAVE: FARELO DE ARROZ; ÓLEO DE ARROZ; BIOFENÓIS; TOCOFERÓIS; $\gamma$-ORIZANOL.

* Mestranda em Ciência e Tecnologia Agroindustrial, Departamento de Ciência e Tecnologia Agroindustrial, Universidade Federal de Pelotas, (UFPel), Pelotas, Rio Grande do Sul (e-mail: vanessapestana@yahoo.com.br).

** Professores, Departamento de Ciência dos Alimentos, UFPeL, Pelotas, Rio Grande do Sul (e-mail: zambiazi@ufpel.edu.br; sidcar@ufpel.edu.br). 


\section{INTRODUÇÃO}

O arroz (Oryza sativa L.) surgiu no sudoeste Asiático em 5.000 a.C., tendo posteriormente se expandido para a Índia e para a Europa. Em meados do século III, essa cultura foi introduzida pelos espanhóis nos países das Américas do Sul e Central e em 1685 chegou aos Estados Unidos da América (EUA). No Brasil, essa cultura foi introduzida pelos portugueses nos primeiros anos após o descobrimento (LEMOS e SOARES, 1999).

Segundo LEMOS e SOARES (1999) o arroz ocupa posição de destaque no celeiro mundial como o cereal mais consumido por todos os povos, sendo superado em produção apenas pelo trigo.

O Brasil, grande produtor de arroz, ocupa a sexta posição no mercado mundial com produção estimada de 8.100 milhões de toneladas de grãos beneficiados na safra 2005/2006, frente à produção mundial de 405.620 milhões de toneladas (KAISER et al., 2005).

O farelo, um dos subprodutos resultantes do beneficiamento do arroz, representa de $8 \%$ a $11 \%$ do peso total do grão, sendo obtido a partir do seu polimento (PARRADO et al., 2006).

O farelo de arroz apresenta aspecto farináceo, fibroso e suave ao tato. O pericarpo, o tegumento, a camada de aleurona e o gérmen (embrião) são eliminados durante a operação de polimento na forma de farelo de arroz, restando o endosperma (grão de arroz polido) (HOSENEY, 1991; LAKKAKULA, LIMA, WALKER, 2004).

Efetuou-se revisão de literatura sobre a caracterização, o mercado e as aplicações do farelo e óleo de arroz, visando compilar informações úteis para pesquisadores da área de alimentos ou de fármacos e ainda com a expectativa de motivar novas pesquisas sobre potenciais empregos desses produtos.

\section{COMPOSIÇÃO DO FARELO DE ARROZ}

O farelo de arroz contém teores variáveis de amido proveniente do endosperma, além de resíduos da casca e de fragmentos de grão, devido ao processo de descasque e polimento do cereal. Em farelo de boa qualidade, esses contaminantes são indesejáveis e devem ser evitados tanto quanto possível (CARVALHO e VIEIRA, 1999). O percentual mais representativo das vitaminas, fibras, proteínas e minerais do grão de arroz encontra-se nas camadas que originam o farelo.

As características físicas e químicas do farelo de arroz dependem de fatores como, cultivar, tratamento do grão antes do beneficiamento, sistema de beneficiamento empregado e grau de polimento ao qual o grão foi submetido. Dessa forma, os valores expressos na literatura para composição do farelo de arroz mostram grande variação que reflete a influência desses fatores na composição do produto final. Assim, tornou-se prática comum de mercado especificar os limites máximos e mínimos de tolerância para os componentes majoritários. Embora a legislação brasileira não estabeleça padrões de qualidade para farelo de arroz, a indústria de transformação do arroz recomenda como parâmetros os valores indicados na Tabela 1.

De acordo com a origem, expressivas variações podem ser encontradas para a composição química do farelo de arroz. A avaliação de produtos oriundos dos EUA, Espanha, Itália, Japão, México, Nepal e Sri Lanka revelou teores de proteínas entre 11,5 a 17,2\%; teores de lipídeos variando de 12,8 a 22,6\%; fibra bruta de 6,2 a 14,4\%; extrato não-nitrogenado entre 33,5 e 53,5\%, e percentual de cinzas na faixa de 8,0 e 15,4\% (BERMUDES, 1994).

O farelo de arroz constitui excelente fonte de minerais, proteínas e óleo, destacando-se pelo expressivo teor de vitaminas (CARVALHO e VIEIRA, 1999; PARRADO et al., 2006). O elevado conteúdo de lipídeos do farelo de arroz (entre 12,8 e 22,6\%), aliado ao seu baixo valor comercial, justificam seu emprego majoritário como matéria-prima para indústria de extração de óleo comestível (SILVA, SANCHES e AMANTE, 2001). 


\begin{tabular}{lc}
\hline Componentes & Tolerância \\
\hline Gordura & $16 \%$ mínimo \\
Proteína & $13 \%$ mínimo \\
Fibra da dieta total & $20 \%$ mínimo \\
Fibra bruta & $9 \%$ máximo \\
Cinza & $10 \%$ máximo \\
Cinza (farelo parboilizado) & $15 \%$ máximo \\
Umidade & $12 \%$ máximo \\
Ácidos graxos livres (FFA) & $4 \%$ máximo \\
Sílica (SiO S $_{\text {Carbonato de cálcio (CaCO }}$ ) & $0,1 \%$ máximo \\
Carboilizado) & $2 \%$ máximo \\
Carbonato de cálcio (farelo parboimo & $6 \%$ máximo \\
\hline
\end{tabular}

Fonte: SAUNDERS (1990).

O farelo de arroz desengordurado contém cerca de 15\% de proteínas e 15\% fibras, tendo cromo e cobre como principais minerais que exercem importante papel na formação de insulina. Além disso, contém zinco e magnésio (importantes para o desenvolvimento) e alto conteúdo em vitamina $\mathrm{A}_{12}$. O farelo de arroz desengordurado pelletizado, por representar excelente fonte protéica, é amplamente utilizado como componente na formulação de rações para animais (MASSARO e PINTO, 2002; HAMADA, 2000; FARREL e HUTTON, 1990). Tanto o farelo quanto o óleo extraído do farelo contêm ainda inúmeros componentes minoritários, enquadrados na categoria de biofenóis. Esses estão relacionados com diversos benefícios à saúde humana como, por exemplo, a redução do nível de colesterol sangüíneo (RODRIGUES, PESSÔA FILHO e MEIRELLES, 2004).

\section{ESTABILIDADE DO FARELO DE ARROZ}

A conservação do farelo de arroz "in natura" torna-se problemática pela ação enzimática durante o armazenamento, que leva à decomposição dos triacilgliceróis e à conseqüente geração de ácidos graxos livres. Os ácidos graxos livres produzem sabor ácido e desagradável que compromete a utilização do farelo para consumo humano e como matéria-prima para extração de óleos comestíveis (CARVALHO et al., 1999; RODRIGUES, ONOYAMA e MEIRELLES, 2006). Em clima quente, as enzimas hidrolizam rapidamente o óleo elevando consideravelmente a acidez livre em poucas horas. Nessa condição, o óleo também é oxidado e agrega odores e sabores rançosos. Além disso, ocorrem perdas de componentes alimentícios valiosos como vitaminas e antioxidantes.

Em regiões tropicais (com alta umidade e temperatura) e também em condições precárias de higiene, o farelo de arroz fresco torna-se inaceitável em poucos dias até mesmo para alimentação animal. Para evitar essa degradação, diferentes tecnologias são aplicadas para conservar o valor alimentício desse produto (que íntegro é muito valioso).

A enzima presente no farelo de arroz, responsável pela degradação dos lipídeos neutros e elevação da acidez é a lípase. Essa precisa ser inativada rapidamente para tornar o farelo estável e adequado ao armazenamento e ao emprego como matéria-prima alimentícia (LAKKAKULA, LIMA e WALKER, 2004). A extrusão termoplástica, método tradicional de estabilização do farelo de arroz, baseia-se na aplicação de calor $\left(125-135^{\circ} \mathrm{C}\right)$ durante $1 \mathrm{a} 3$ segundos, sendo importante que o produto apresente teor de umidade entre 11 e 15\%. Concomitantemente à inativação enzimática podem ocorrer alterações desejáveis na cor e sabor do produto. No entanto, esse processo também pode produzir efeitos indesejáveis como a desnaturação protéica e perdas de vitaminas (CARVALHO e VIEIRA, 1999).

Métodos alternativos de estabilização envolvem o aquecimento por microondas e mais recentemente o aquecimento ôhmico que tem se mostrado bastante promissor. Esse último baseia- 
se na passagem de corrente elétrica alternada através da amostra, a qual gera aquecimento dependente de sua resistência elétrica. Temperaturas superiores a $100^{\circ} \mathrm{C}$ são alcançadas no farelo de arroz, sendo que amostras estabilizadas por esse processo evidenciaram aumento no rendimento da extração do óleo (LAKKAKULA, LIMA e WALKER, 2004).

Estudos sobre a estabilização do farelo de arroz, utilizando amostras de farelo obtido do polimento de arroz integral e do polimento de arroz parboilizado foram realizados. O farelo de arroz parboilizado apresentou-se estável, após quatro meses sem necessidade de processo complementar para garantir sua qualidade, indicando que a parboilização pode ser suficiente para gerar farelo estabilizado (SILVA, SANCHES e AMANTE, 2006).

A temperatura empregada durante o processo hidrotérmico de parboilização é suficiente para inativar a enzima lipase, protegendo o farelo obtido por esse processo de hidrólise da fração lipídica pela ação enzimática.

A estabilização dos componentes lipídicos do farelo de arroz também pode ser alcançada por meio de tratamento com proteases, no qual a atividade da enzima lipase é afetada. Esse tratamento enzimático tem se mostrado bastante efetivo e benéfico para minimizar alterações na composição inicial do farelo de arroz. Além disso, reduz perdas de componentes essenciais como amino-ácidos, gorduras e alguns micronutrientes (especialmente o orizanol).

O processo enzimático envolve a hidrólise usando mistura de endoproteases (tripsina e quimiotripsina) em biorreator, com temperatura e $\mathrm{pH}$ controlados $\left(60^{\circ} \mathrm{C}-\mathrm{pH}\right.$ 8). As proteínas do farelo de arroz alcançam grau de hidrólise de $20 \%$ após 40 minutos de reação. O processo envolve etapas como centrifugação, filtração e concentração e resulta em xarope escuro completamente solúvel em água. A atividade da lipase é inicialmente aumentada neste processo, mas após cerca de 15-20 min começa a diminuir sendo totalmente eliminada depois de $1 \mathrm{~h}$ de reação. O processo também oferece benefícios em relação ao conteúdo de orizanol e vitamina $E$, que são cerca de 3 vezes maiores no farelo hidrolisado que no bruto (PARRADO et al., 2006).

O farelo de arroz estabilizado apresenta-se sob a forma de pó finamente granulado, de cor marrom clara e sabor de noz tostada. Alcança vida útil de seis meses, quando armazenado sob temperaturas inferiores a $30^{\circ} \mathrm{C}$ (SAUNDERS, 1990). Esse produto pode servir como matéria-prima para diversos alimentos processados (cereais matinais, granola em tabletes e "snacks") e certos alimentos extrusados, além de ser empregado com sucesso em produtos de panificação e confeitaria.

\section{APLICAÇÕES DO FARELO DE ARROZ}

A partir do farelo, desengordurado ou não, pode-se extrair proteína ainda pouco usada em produtos alimentícios, apesar de seu grande potencial de aplicação. Tem-se como vantagem da proteína do farelo de arroz a ausência de efeitos indesejáveis em indivíduos intolerantes ou alérgicos ao glúten. Bons resultados como condicionador de massas em produtos de panificação tem sido obtidos por melhorar a retenção do gás e as propriedades de mistura das massas (ABDULHAMID e LUAN, 2000; AOE et al.,1993).

A digestibilidade da proteína do farelo de arroz encontra-se em torno de 70-75\%. Quando se realiza a remoção das fibras e do ácido fítico pela extração por álcali diluído, a digestibilidade protéica alcança valores superiores a 90\% (CARVALHO e VIEIRA, 1999).

O farelo de arroz apresenta grande potencial como emulsificante em produtos que contêm alto teor de gordura pelo seu poder relativamente alto de absorção de óleo. Além disso, pode substituir as gomas comerciais e amidos modificados usados como estabilizantes e emulsificantes em molhos prontos (ABDULHAMID e LUAN, 2000).

O concentrado protéico, obtido do farelo, apresenta grande capacidade de emulsificação e estabilização de emulsões, sendo bastante apropriado para utilização em imitações de produtos 
cárneos. Quando utilizado em substituição à proteína animal é capaz de manter a qualidade nutricional do alimento (CARVALHO e VIEIRA, 1999).

Estudos de CHANDI e SOGI (2007) demonstraram que a capacidade emulsificante do concentrado de proteína do farelo de arroz (Basmati 360) varia entre 24 e $74 \%$. As emulsões produzidas apresentaram-se razoavelmente estáveis sob diferentes condições de $\mathrm{pH}$, concentrações de sal e de açúcar. Os mesmos autores mencionaram que as propriedades funcionais de concentrados de proteína do farelo de arroz são comparáveis às da caseína, evidenciando bom potencial desse produto para as indústrias de alimentos.

A qualidade da proteína do farelo de arroz só é inferior à da aveia, superando a do trigo e a do milho. Essa proteína hipoalergênica contém quantidades apreciáveis de lisina. Seu perfil de aminoácidos a torna ingrediente apropriado para formulações de alimentos infantis (WANG et al., 1999).

O uso das proteínas extraídas do farelo de arroz desengordurado como ingrediente nutracêutico tem sido considerado favorável devido sua estabilidade térmica (TANGE et al., 2003).

As fibras assumem importância no farelo de arroz e devido sua capacidade de absorção de água e óleo podem ser utilizadas no desenvolvimento de grande variedade de produtos industrializados (CARVALHO e VIEIRA, 1999; ABDULHAMID e LUAN, 2000).

Estudos mostram a capacidade da fibra dietética do farelo de arroz desengordurado de ligarse a água, sendo suas características comparáveis às da fibra comercial do açúcar da beterraba (FIBREX). O farelo de arroz consiste em quase $27 \%$ de fibra dietética e desta forma está fortemente relacionado com a redução do teor de colesterol sangüíneo. Pode-se ainda associar a ingestão de fibra do arroz com a prevenção de doenças cardiovasculares, diabetes, diverticulose e câncer de cólon (ABDULHAMID e LUAN, 2000).

KIM, GODBER e PRINAYWIWATKUL (2000) elaboraram e avaliaram bolos de carne reestruturados contendo fibra de arroz e óleo de arroz. Constataram que os bolos com fibra de arroz ou com óleo do arroz apresentam estabilidade oxidativa maior durante o armazenamento do que os bolos de carne sem esses componentes. Em trabalho semelhante, HUANG et al. (2005) avaliaram a influência do percentual de farelo de arroz nas características sensoriais de bolos de carne reestruturados. Verificaram que a adição de até $10 \%$ de farelo de arroz não produz diferença significativa no gosto, textura e aceitabilidade dos bolos em relação ao bolo-padrão (sem farelo). Entretanto, a adição de $15 \%$ de farelo de arroz interfere negativamente nesses atributos. Constataram também, que o tamanho das partículas do farelo afetou profundamente as propriedades sensoriais e físico-químicas dos produtos de carne. Os bolos de carne adicionados de farelo com partículas menores apresentaram melhores características sensoriais do que os preparados com farelo de partículas maiores.

Importante aplicação do resíduo resultante da neutralização do óleo de farelo de arroz tem sido a produção de vanilina (3-metoxi-4-hidrobenzaldeido). Essa tecnologia inclui a fermentação por Aspergillus niger e Pycnoporus cinnabarinus, e baseia-se na transformação do ácido ferúlico (ZHENG et al., 2007). A vanilina constitui flavorizante utilizado universalmente em alimentos, bebidas e produtos farmacêuticos (PRIEFERT, RABENHORST e STEINBUCHEL, 2001).

\section{BENEFÍCIOS À SAÚDE}

Estudos têm demonstrado que dietas com 10\% de hemicelulose, proveniente do farelo de arroz, aumentam o número de leucócitos e de linfócitos no sangue de ratos. O polissacarídeo derivado do farelo de arroz, designado de RON, quando administrado por via oral em camundongos demonstrou atividade antitumoral. Estudos realizados in vitro evidenciaram que esse polissacarídeo estimula os macrófagos aumentando a produção de interleucina e gerando efeito tumoricida (CARVALHO e FELIPPE JUNIOR, 2006).

O farelo de arroz na dose de $36 \mathrm{~g}$ ao dia diminuiu a excreção renal de cálcio e aumentou a excreção de ácido em mulheres na menopausa submetidas a dieta com $1 \mathrm{~g}$ de cálcio/dia. Em pessoas 
com hipercalciúria e formadoras de cálculos renais, o tratamento com farelo de arroz reduziu drasticamente a formação dos cálculos (JARIWALLA, 2001).

Os níveis de colesterol e triglicerídeos de ratos alimentados com dietas ricas em colesterol foram reduzidos quando se empregou concentrado de substâncias bioativas do óleo do farelo de arroz como suplemento (HA et al., 2005). Considera-se que a presença abundante de cicloartenol ferulato inibe a atividade do colesterol esterase no fígado, a qual reduz os níveis de colesterol circulante.

O farelo de arroz tem mostrado promissores benefícios à saúde na prevenção de diferentes disfunções como, câncer, hiperlipidemia, hipercalciúria, cálculos renais em crianças e para doenças cardíacas (JARIWALLA, 2001). Isso não ocorre quando se ingere o arroz branco (polido). O farelo de baixíssimo custo e elevadas propriedades nutricionais, no entanto, destina-se para alimentação animal (PARRADO et al., 2006).

O farelo do arroz apresenta alta concentração de fitinas (9,5 a 14,5\%), matéria-prima fundamental para a obtenção de ácido fítico e fitatos. O ácido fítico tem como função mais importante a quelação de metais e ao contrário do que se acreditava anteriormente, esse ácido é de suma importância na fixação do ferro. Além disso, exerce função antioxidante e previne cálculos renais na bexiga e câncer de cólon. Também promove a limpeza da placa bacteriana dos dentes e produz efeito desodorante corporal, incluindo mau hálito. Estudos recentes têm enfatizado a importância da ação carcinostática do ácido fítico. Esse importante ácido oriundo do farelo de arroz pode, ainda, ser utilizado como aditivo alimentar para realçar o sabor de carnes e peixes (AMATO, 2006).

O farelo de arroz e seu óleo representam importante fonte de fitosterol, fitoquímico relacionado com a diminuição do colesterol em humanos. Por seu caráter emulsificador tem amplo uso na indústria de cosméticos em xampus, cremes e emolientes. A principal fonte de fitosteróis ainda é a soja, entretanto expressivos teores têm sido encontrados no óleo de arroz bruto (INDIRA et al., 2000). Mediante modificação química do fitosterol pode ser obtido o estanol, produto que também apresenta efeito na redução do colesterol.

O inositol encontra-se concentrado no farelo de arroz nas formas de fitato de cálcio ou sal misto de magnésio (fitina). Classificado como vitamina, inositol está relacionado com o crescimento. É utilizado como aditivo em produtos lácteos infantis, como suplemento natural em bebidas especiais para atletas e em rações para o desenvolvimento de peixes. Estudos revelaram que o inositol atua prevenindo a arteriosclerose e acelerando a absorção do cálcio no organismo (AMATO, 2006). Outro importante fitoquímico do farelo de arroz é o $\gamma$-orizanol, cuja denominação já acusa o vínculo com o arroz (Oriza sativa). Classificado como antioxidante e sendo mais resistente ao calor torna-se mais efetivo que os tocoferóis. $\mathrm{O} \gamma$-orizanol consiste numa complexa mistura de ésteres do ácido ferúlico com alcóois triterpenos e esteróis. Mais de 23 ésteres dos ácidos ferúlico e caféico já foram identificados no $\gamma$-orizanol, sendo os principais componentes (mais de $80 \%$ da fração do $\gamma$-orizanol) o 24-metileno cicloartenil ferulato, cicloartenilferulato ou cicloartenol, $\beta$-sistoterilferulato e campesterilferulato ou campesterol (KIM et al., 2001; FANG, YU e BADGER, 2003). Entre as múltiplas ações desse composto mencionam-se os efeitos no crescimento, combate a doenças cefálicas e cervicais, minimização dos sintomas da menopausa, combate à anemia, tratamento de úlceras do estresse e como coadjuvante no tratamento de doenças circulatórias. As propriedades do $\gamma$-orizanol justificam seu amplo uso, seja como medicamento, na composição de cosméticos, como agente antienvelhecimento da pele e até como filtro solar. Esse fitosterol apresenta efeito semelhante aos hormônios (esteróides) quando usado na alimentação de cavalos de corrida em que seu emprego é seguro e legalmente permitido (XU, HUA e GODBER, 2001; AMATO, 2006; WILSON et al., 2007).

Diversos estudos têm atestado a alta atividade antioxidante do $\gamma$-orizanol, que atua como agente cardioprotetor, redutor de colesterol plasmático e da absorção de colesterol hepático e agente de prevenção da arteriosclerose (SILVA, SANCHES e AMANTE, 2001; WILSON et al., 2000). Sua utilização tem sido ainda bastante restrita, principalmente devido ao alto custo desse produto atribuído em grande parte à etapa de purificação dessas frações. Outro aspecto limitante é a relativa falta de estudos sobre a atividade antioxidante desse componente quando associado com outros constituintes dos alimentos (GONG-YUANSSHENG e YAO-HUIYUAN, 2001; XU, HUA e GODBER, 2001). 
WILSON et al. (2007) ministraram orizanol e ácido ferúlico na proporção de 0,5\% em dietas para ratos hipercolesterolêmicos. Observaram que as dietas contendo $10 \%$ de óleo de arroz e 0,5\% de orizanol diminuíram significativamente a concentração dos triglicerídeos plasmáticos. As dietas contendo ácido ferúlico e orizanol produziram significativa redução nos níveis de lipídeos oxidados no plasma. Os ratos alimentados com orizanol excretaram significativamente mais coprostenol e colesterol em suas fezes. Ainda, as dietas com ácido ferúlico aumentaram os níveis séricos de vitamina E. Segundo os mesmos autores, o orizanol e o ácido ferúlico podem exercer propriedades antiarterogênicas similares, mas mediante mecanismos diferentes.

O efeito da atividade antioxidante dos ésteres do ácido ferúlico e tocoferóis foi estudado por NYSTRÖM et al. (2007). Verificaram que esses compostos reduziram a formação de polímeros em altas temperaturas, tanto quando foram utilizados juntos quanto individualizados, sendo que nenhum efeito de sinergismo foi observado entre eles. Os ésteres do ácido ferúlico foram degradados em menor intensidade que o alfa-tocoferol, indicando o potencial do sitostanil ferulato para ser empregado sob altas temperaturas. A mistura de ésteres do ácido ferúlico, comumente conhecida como $\gamma$-orizanol, varia bastante de acordo com o cereal que a origina (arroz, milho, centeio ou trigo). Enquanto no arroz domina o dimetilesterol (cicloartenol e 24-metilenecycloartanol) nos demais cereais predominam os desmetilterols (sitosterol, campesterol e suas formas saturadas, estanóis).

A atividade antioxidante dos ésteres do ácido ferúlico é baseada na doação de hidrogênio do grupo hidroxil do ácido ferúlico. Assim, esses compostos atuam como os demais antioxidantes comumente utilizados na indústria de alimentos (BHT, BHAe TBHQ). Esses ésteres são compostos polares com baixo peso molecular e solubilidade limitada em óleos, sendo facilmente volatilizados. Desta forma, longos períodos de aquecimento podem reduzir o efeito antioxidante dos mesmos. A solubilidade em óleo dos ésteres do ácido ferúlico pode ser aumentada quando ocorre a esterificação desses componentes com outros compostos não-polares presentes no óleo, como o fitosterol. Esse processo também promove o aumento da estabilidade térmica dos óleos. SHOPOVA e MILKOVA (2000) avaliaram a decomposição térmica desses compostos e verificaram que os ésteres do ácido ferúlico são mais estáveis do que o ácido ferúlico livre sob altas temperaturas, ebulição e fritura.

O óleo de farelo de arroz contém cerca de 1,5\% de orizanol e por esse fato tem sido reconhecido como bastante adequado para emprego em frituras (NORTON, 1995).

Estudos têm demonstrado que a capacidade do $\gamma$-orizanol para inibir a oxidação lipídica depende de sua concentração. Na dose de $10 \mathrm{mmol} \mathrm{kg}^{-1} \mathrm{o} \gamma$-orizanol tem atividade comparável a do antioxidante sintético butil hidroxi tolueno (GERTZ, KLOSTERMANN e KOCHHAR, 2000; HUANG et al., 2002; JULIANO et al., 2005; NYSTRÖM et al., 2005).

Tocotrienóis do óleo do farelo de arroz têm sido relacionados com a diminuição do colesterol LDL mediante redução da atividade HMG-CoA reductase, mas segundo KERCKHOFFS et al. (2000) os resultados são controversos. Esses autores compararam o efeito dos tocotrienóis e de um inibidor da reductase de HMG-CoA nos níveis de colesterol LDL em humanos hipercolesterolêmicos. Os resultados demonstraram que nenhum dos tratamentos afetou os níveis de colesterol LDL. No entanto, pesquisas de MINHAJUDDIN, BEG e IQBAL (2005) avaliaram o efeito hipolipidêmico e antioxidante de frações ricas em tocotrienóis isoladas do óleo de farelo de arroz em ensaios biológicos com ratos hiperlipidêmicos. Doses de 0 a $50 \mathrm{mg} / \mathrm{kg} / \mathrm{dia}$ de frações ricas de tocotrienóis foram ministradas por uma semana, tendo sido verificado que a dose de $8 \mathrm{mg} / \mathrm{kg} / \mathrm{dia}$ diminuiu significativamente os parâmetros lipídicos, ácido triobarbitúrico e dienos conjugados.

\section{6 ÓLEO DE FARELO DE ARROZ}

O óleo comestível obtido do farelo de arroz é apreciado especialmente no leste da Ásia. No Japão, aproximadamente 80 mil toneladas desse óleo são consumidas anualmente. Esse óleo recebeu atenção por apresentar grande quantidade de compostos nutracêuticos como o orizanol, tocoferóis e tocotrienóis, sendo os dois últimos componentes da família da vitamina E (DANIELSKI et al., 2005). 
O alto valor energético do farelo de arroz deve-se, em parte, ao seu elevado teor de lipídeos (SILVA, SANCHES e AMANTE, 2001). O óleo do farelo de arroz é constituído por cerca de 68 a $71 \%$ de triacilgliceróis, 2 a 3\% de digliceróis, 5 a $6 \%$ de monogliceróis e 2 a 3\% de ácidos graxos livres. Ainda, apresenta frações variáveis de glicolipídios (5 a 7\%), fosfolipídios (3 a 4\%), ceras (2 a 3\%) e lipídeos insaponificáveis (aproximadamente 4\%) (MCCASKILL e ZHANG, 1999). O conteúdo total dos ácidos graxos corresponde a cerca de 18\% de ácidos graxos saturados, $45 \%$ de ácidos graxos monoinsaturados e $37 \%$ de ácidos graxos poliinsaturados. Os principais ácidos graxos saturados são os ácidos palmítico (14-17\%) e esteárico (2,0-2,5\%) e os principais insaturados são os ácidos oléico (40-45\%), linoléico (35-37\%) e linolênico (1-2\%) (ZAMBIAZI, 1997).

Verifica-se, especialmente nas áreas de nutrição e bioquímica, a tendência de agrupar os ácidos graxos insaturados em famílias conhecidas como ômega ( $\omega)$. Nessa classificação, os ácidos linolênico, linoléico e oléico são enquadrados, respectivamente, nas categorias $\omega-3, \omega-6$ e $\omega$-9. 0 ácido oléico destaca-se como um dos ácidos graxos mais amplamente distribuído na natureza, sendo encontrado praticamente em todos os óleos e gorduras de origem animal e vegetal (ZAMBIAZI, 1997). Sob o ponto de vista nutricional, os ácidos linoléico e linolênico são considerados "ácidos graxos essenciais" e como não podem ser sintetizados pelo organismo humano devem ser ingeridos através da dieta (SILVA, SANCHES e AMANTE, 2001).

Como o óleo do farelo de arroz contém quantidade muito pequena de ácido linolênico sua associação com o óleo de girassol, na proporção de 70:30 (v/v), pode reunir as vantagens do alto teor de matéria insaponificável do óleo de arroz e o alto teor de ácido linolênico do óleo de girassol. A mistura desses dois óleos parece indicar ação sinérgica, que gera maiores benefícios à saúde do que a simples soma das propriedades individuais de cada óleo.

O óleo de farelo de arroz, quando comparado com outros óleos evidencia algumas vantagens. Contém importantes micronutrientes, é muito resistente à oxidação durante a cocção, seu gosto mais neutro o torna ótimo para saladas e suas propriedades nutricionais o fazem disputar espaço com os óleos de gergelim e oliva. Como desvantagem tem-se o maior custo em relação a outros óleos devido maior complexidade no processo de seu refino, fato responsável por sua menor produção em alguns países (RODRIGUES, ONOYAMA e MEIRELLES, 2006).

A capacidade hipolipidêmica do óleo do farelo de arroz não é inteiramente explicada por sua composição em ácidos graxos. O que o torna diferente dos outros óleos é o seu elevado conteúdo de matéria-insaponificável, em particular, componentes da família dos esteróis da planta como, os tocotrienóis, tocoferóis, orizanóis, ésteres do ácido ferúlico, fitosteróis e alcóois triterpênicos (WILSON et al., 2007; QURESHI et al. 1991).

O óleo de arroz apresenta benefícios ímpares à saúde, os quais podem ser atribuídos principalmente ao alto nível de matéria insaponificável. Do conteúdo de matéria insaponificável, $43 \%$ são esteróis e correlatos (orizanóis, tocoferóis e tocotrienóis), 28\% ácidos triterpênicos, 10\% 4-metil esteróis e menos de 19\% representam compostos polares (esqualeno, outros hidrocarbonetos e alcóois alifáticos) (SAYRE e SAUNDERS, 1990; KIM et al., 2001; SHIN et al., 1997; RODRIGUES, ONOYAMA e MEIRELLES, 2006)

O óleo do farelo de arroz apresenta expressivo conteúdo de tocoferóis e tocotrienóis, conhecidos por tocóis (família de isômeros com atividade de vitamina E) (RODRIGUES, ONOYAMA e MEIRELLES, 2006). Os tocóis representam fator importante sob o ponto de vista de estabilidade oxidativa (KIM e GODBER, 2001). Os tocoferóis alfa, gama e delta são os principais representantes da família dos tocóis no óleo do farelo de arroz e representam cerca de $1.000 \mathrm{mg} / \mathrm{kg}$ de óleo (ZAMBIAZI, 1997). Devido ao expressivo teor desses componentes e ao caráter funcional dos mesmos, a utilização do óleo de arroz tem aumentado nos países ocidentais (ORTHOEFER, 1996; JARIWALLA, 2001; KIM e GODBER, 2001)

O óleo do farelo de arroz apresenta abundância de $\gamma$-orizanol (cerca de $3.000 \mathrm{mg} / \mathrm{kg}$ de óleo), o que the confere alto valor comercial (GONG-YUANSSHENG e YAO-HUIYUAN, 2001; XU, HUA e GODBER, 2001).

A extração do óleo do farelo de arroz é complexa e seu refino dificultado pela elevada acidez, alto conteúdo de insaponificáveis e de ceras $(3,0 \%)$ e por sua forte coloração (ABOISSA, 2006). 


\section{NOVAS TECNOLOGIAS}

A matéria insaponificável do óleo de arroz, que no óleo cru é da ordem de 4 a $5 \%$, está relacionada com diversos benefícios à saúde humana. Entretanto, após o refino esse valor fica reduzido para cerca de 3\%. O processo de refino de óleos vegetais é responsável por significativa perda dos compostos fitoquímicos, especialmente na etapa de neutralização pelo o processo tradicional com uso de soluções alcalinas (ORTHOEFER, 1996; DUNFORD, TEEL e KING, 2003; RODRIGUES, ONOYAMA e MEIRELLES, 2006). Alto teor de acidez exige grande quantidade de água e reagentes alcalinos, operações que geram muitos resíduos e consomem grande quantidade de energia.

Para a manutenção dos fitoquímicos tem sido sugerido o processo de neutralização com solventes orgânicos, capazes de reduzir os ácidos graxos livres mediante processo de extração líquido-líquido (RODRIGUES, ONOYAMA e MEIRELLES, 2006). Esse método baseia-se na diferença de solubilidade dos ácidos graxos livres e triacilgliceróis em solvente apropriado. O processo pode ser conduzido em baixas temperaturas e em pressão atmosférica, o que representa baixo consumo energético e formação de pequena quantidade de resíduos (RODRIGUES, PESSÔA FILHO e MEIRELLES, 2004). Outro processo que tem sido proposto para desacidificação do óleo de arroz é o fracionamento com dióxido de carbono supercrítico. O método baseia-se na operação em contra-corrente (óleo e $\mathrm{CO}_{2}$ ), empregando baixas pressões (138 bar) e altas temperaturas $\left(80^{\circ} \mathrm{C}\right)$ (DUNFORD, TEEL e KING, 2003).

O uso da tecnologia de membranas está sendo estudado como alternativa para substituir o refino convencional, devido ao baixo consumo de energia. A operação ocorre em temperatura ambiente sem a adição de componentes químicos e evita a perda de compostos benéficos que atuam como antioxidantes. As pesquisas objetivam degomar, desacidificar e branquear o óleo usando membranas com e sem o emprego de solventes. Entretanto, essas membranas ainda não estão disponíveis comercialmente (SARAVANAN, BHOSLE e SUBRAMANIAN, 2006).

A extração supercrítica com dióxido de carbono $\left(\mathrm{SC}-\mathrm{CO}_{2}\right)$ pode superar os aspectos negativos da técnica tradicional de extração com hexano, tais como a contaminação do soluto com os resíduos do solvente e a termodegradação. $\mathrm{O} \mathrm{CO}_{2}$, solvente não-tóxico, pode ser facilmente e completamente removido dos produtos. Além disso, não é corrosivo, nem inflamável e está disponível em grandes quantidades com elevada pureza. Embora a extração com fluido supercritico forneça rendimentos totais como os da extração tradicional com hexano, o processo obedece dois passos de acordo com a seletividade. Em baixas pressões ocorre a extração dos ácidos graxos livres e em altas pressões obtém-se triacilglicerídeos com alta pureza. Vários pesquisadores têm proposto o uso de $\mathrm{SC}-\mathrm{CO}_{2}$ para separar ceras, orizanóis e frações de ácidos graxos livres do óleo de farelo de arroz (GARCIA et al., 1996; KUK e DOWD, 1998; XU e GODBER, 2000).

GARCIA et al. (1996) executaram a extração do óleo do farelo de arroz com uso do SC-CO , utilizando pressão de 280 bar e temperatura variando entre 40 e $70^{\circ} \mathrm{C}$. Comparado esse óleo com o obtido pela extração com hexano, o seu conteúdo de ceras e de ácidos graxos de cadeia longa foram $50 \%$ menores que o óleo extraído com hexano. KUK e DOWD (1998) executaram extrações em níveis diferentes de pressão e temperatura $\left(400-600\right.$ bar e $\left.70-100^{\circ} \mathrm{C}\right)$, tendo verificado que a quantidade de ácidos graxos livres presentes no extrato aumentou de 1,5\% a 3,0\% com a elevação da temperatura e da pressão.

No trabalho publicado por XU e GODBER (2000), a separação de gama-oryzanol do farelo de arroz por fluído supercrítico foi realizada a 680 bar. Os resultados mostraram que a quantidade de orizanol obtida no extrato foi de até 80 vezes maior do que a obtida pela extração com hexano.

\section{CONSIDERAÇÕES FINAIS}

O aproveitamento integral de determinada cultura agrícola de forma mais racional é o objetivo da indústria e alvo de estudos por parte dos pesquisadores. Neste sentido, o farelo de arroz por seu grande valor nutricional e abundância em compostos antioxidantes tem evidenciado enorme potencial como matéria-prima para diversos produtos alimentícios e farmacêuticos. 
A utilização do farelo de arroz para consumo humano no Brasil ainda é bastante reduzida, no entanto, a tendência do mercado mundial e as pesquisas apontam para promissoras aplicações desse produto.

\section{ABSTRACT \\ RICE BRAN: CHARACTERISTICS, HEALTH BENEFITS AND APPLICATIONS}

The rice bran composition, stability, applications and health benefits were discussed in this review. Aspects of biophenols composition of rice bran oil and new technologies used during extraction and refining of the oil also were approached. The rice bran is a rice by-product and it evidences high using possibilities and also great economical potential. Still is reduced the human consumption of bran and rice bran oil in Brazil, however, the trend of the world market and the research shows promising applications of this product.

KEY-WORDS: RICE BRAN; RICE BRAN OIL; BIOPHENOLS; TOCOPHEROL; $\gamma$ ORYZANOL.

\section{REFERÊNCIAS}

1 ABDULHAMID, A.; LUAN, Y.S. Functional properties of dietary fiber prepared from defatted rice bran. Food Chemistry, v.68, n.1, p.15-19, 2000.

2 ABOISSA. Empresa Aboissa de Óleos Vegetais. Farelo e óleo de arroz. Disponível em: <http://www.aboissa.com.br/ arroz/index.htm>. Acesso em: 04 nov. de 2006.

3 AMATO, G.W. Farelo do Arroz: uma nova visão. Porto Alegre: Centro de Excelência do arroz - IRGA, 2006. Disponível em: http://www.irga.rs.gov.br/index.php?action=artigo_detalhe\&id=28. Acesso em: 15 set. de 2006.

4 AOE, S.; ODA, T.; TATSUMI, K.; YAMAUCHI, M.; AYANO, Y. Extraction of soluble dietary fibers from defatted rice bran. Cereal Chemistry, v.70, n.4, p.423-425, 1993.

5 BERMUDES, R. F. Avaliação do farelo de arroz integral em rações para terneiros holandês e jersey desaleitados precocemente. Pelotas, 1994. 242 p. Dissertação (Mestrado em Zootecnia), Faculdade de Medicina Veterinária, Universidade Federal de Pelotas.

6 CARVALHO, R. DE C.; FELIPPE JÚNIOR J. de. Arroz integral: o farelo de arroz possui atividade anti-radical hidroxila, anti-radical superóxido e contém em sua composição: SODCu - Zn. Associação Brasileira de Medicina Complementar. Disponível em: <http://www.medicinacomplementar.com.br/tema180405.asp>. Acesso em: 15 set. de 2006.

7 CARVALHO, J.L.V. de; VIEIRA, N.R. de A. A cultura do arroz no Brasil: usos alternativos. Santo Antônio de Goiás: Embrapa Arroz e Feijão, 1999. p.605-621.

8 CHANDI, G.K.; SOGI, D.S. Functional properties of rice bran protein concentrates. Journal of Food Engineering, v. 79, p. 592-597, 2007.

9 DANIELSKI, L.; ZETZL, C.; HENSE, H.; BRUNNER, G. A process line for the production of raffinated rice oil from rice bran. J. of Supercritical Fluids, v.34, p. 133-141, 2005.

10 DUNFORD, N.T.; TEEL, J.A.; KING, J.W. A continuous countercurrent supercritical fluid deacidification process for phytosterol ester fortification in rice bran oil. Food Research International, v. 36, p.175-181, 2003.

11 FANG, N.; YU, S.; BADGER, T.M. Characterization of triterpene alcohol and sterol ferulates in rice bran using LC-MS/ MS. Journal Agric. Food Chemestry, v.51, p. 3260-3267, 2003.

12 FARREL, D.J.; HUTTON. K. Rice and rice milling by-products. In: THACKER, P.A.; KIRKWOOD, R.N. (eds.). Nontraditional feed sources for use in swine production. Boston: Butterworths, 1990. $512 \mathrm{p}$.

13 GARCIA, A.; LUCAS, A. de; RINCON, J.; ALVAREZ, A.; GRACIA, I.; GARCIA, M.A. Supercritical carbon dioxide extraction of fatty and waxy material from rice bran, J. Am. Oil Chem. Soc., v.73, n.9, p. 1127-1131, 1996.

14 GERTZ, C.; KLOSTERMANN, S.; KOCHHAR, S. P. Testing and comparing oxidative stability of vegetable oils and fats at frying temperature. European Journal of Lipid Science and Technology, v.102, n.8-9, p.543-551, 2000.

15 GONG-YUANSSHENG, Y.; YAO-HUIYUAN, H. Purification and identification of gamma-oryzanol from rice bran. Journal of the Chinese Cereals and Oils Association, v.16, p.30-34, 2001. 
16 HA, T-Y; HAN, S.; KIM, S-R.; KIM, I-H.; LEE, H-Y.; KIM, H-K. Bioactive components in rice bran oil improve lipid profiles in rats fed a high-cholesterol diet. Nutrition Research, v.25, p.597-606, 2005.

17 HAMADA J. S. Characterization and functional properties of rice bran proteins modified by commercial exoproteases and endoproteases. Journal of Food Science, v.65, n.2, p.305-310, 2000.

19 HUANG, D. J.; OU, B. X.; HAMPSCH-WOODILL, M.; FLANAGAN, J. A.; DEEMER, E. K. Development and validation of oxygen radical absorbance capacity assay for lipophilic antioxidants using randomly methylated beta-cyclodextrin as the solubility enhancer. Journal of Agricultural and Food Chemistry, v.50, n.7, p.1815-1821, 2002.

20 HUANG, S.C.; SHIAU, C.Y.; LIU, T.E.; CHU, C.L.; HWANG, D.F. Effects of rice bran on sensory and physico-chemical properties of emulsified pork meatballs. Meat Science, v.70, p. 613-619, 2005.

21 INDIRA, T.N; HEMAVATHY, J; KHATOON, S.; KRISHNA, A.G.G; BRHATTACHARYA, S. Water degumming of rice bran oil: a response surface approach. Journal of Food Engineering, v.43, p. 83-90, 2000.

22 JARIWALLA, R.J. Rice-bran products: phytonutrients with potential applications in preventive and clinical medicine. Drugs Exp. Clin. Res., n.27, p. 17-26, 2001.

23 JULIANO, C.; COSSU, M.; ALAMANNI, M. C.; PIU, L. Antioxidant activity of gamma-oryzanol: mechanism of action and its effect on oxidative stability of pharmaceutical oils. International Journal of Pharmaceutics, v.299, n.1-2, p.146-154, 2005

24 KAISER, V.H.; RUCATTI, E.G.; OLIVEIRA, C.F.; BARATA, T.S. Análise de mercado: Rio Grande do Sul. Informativo IRGA, v.1, n.2, p. 1-7, 2005

25 KERCKHOFFS, D.A.J.M.; MENSINK, R.P.; BRUIN, R. P. de; TRAUTWEIN, E.A.; BROUNS, F.; HORNSTRA, G.I. Tocotrienols from rice bran oil have no effects on levels of LDL cholesterol and markers for cholesterol synthesis and absorption. Atherosclerosis, v. 151, n.1, p. 114-114, Jul. 2000

26 KIM, J.S.; GODBER, J.S. Oxidative stability and vitamin E levels increased in restructured beef roast with added rice bran oil. Journal Food Qual., n. 24, p.17-26, 2001

27 KIM, J.S.; GODBER, J.S.; KING, J.; PRIYAWIWATKUL, W. Inhibition of cholesterol autoxidation by the nonsaponifiable fraction in rice bran in an aqueous model system. Journal of American Oil Chemists' Society, n.78, p. 685-689, 2001.

28 KIM, J. S.; GODBER, J. S.; PRINAYWIWATKUL, W. Restructured beef roasts containing rice bran oil and fiber influences cholesterol oxidation and nutritional profile. Journal of Muscle Foods, v.11, p.111-127, 2000.

29 KUK, M.S.; DOWD, M.K. Supercritical extraction of rice bran. J. Am. Oil Chem. Soc., v.75, n.5, p. 623-628, 1998.

30 LAKKAKULA, N. R.; LIMA, M.H; WALKER, T. Rice bran stabilization and rice bran oil extraction using ohmic heating. Bioresource Technology, v.92, p.157-161, 2004.

31 LEMOS, M.R.B.; SOARES, L.A.de S. Farelo de arroz: um subproduto em estudo. Óleos \& Grãos, v. 7, n. 51, p.40-48, 1999.

32 MASSARO, A. F.; PINTO, L. A. de A. Enriquecimento protéico de farelo de arroz desengordurado com sangue bovino, utilizando a técnica de leito de jorro. Rev. Inst. Adolf Lutz, v.67, n.2, p.77-84, 2002.

33 MCCASKILL, D.R.; ZHANG.F. Use of rice bran oil in foods. Food Technology, v. 53, n.2, p. 50-53, 1999.

34 MINHAJUDDIN, M; BEG, Z. H.; IQBAL, J. Hypolipidemic and antioxidant properties of tocotrienol rich fraction isolated from rice bran oil in experimentally induced hyperlipidemic rats. Food and Chemical Toxicology, v.43, p.747-753, 2005.

35 NORTON, R. A. Quantitation of steryl ferulate and p-coumarate esters from corn and rice. Lipids, v.30, n.3, p.269274,1995

36 NYSTRÖM, L.; ACHRENIUS, T.; LAMPI, A-M.; MOREAU, R. A.; PIIRONEN, V. A comparison of the antioxidant properties of steryl ferulates with tocopherol at high temperatures. Food Chemistry, v.101, p.947-954, 2007.

37 NYSTRÖM, L.; MÄKINEN, M.; LAMPI, A.; PIIRONEN, V. Antioxidant activity of steryl ferulate extracts from rye and wheat bran. Journal of Agricultural and Food Chemistry, v. 53, n.7, p.2503-2510, 2005.

38 ORTHOEFER, F.T. Rice bran oil: healthy lipid source. Food Technology, n.50, p. 62-64, 1996. 
39 PARRADO, J.; MIRAMONTES, E.; JOVER, M.; GUTIERREZ, J. F.; TERÁN, L. C. DE; BAUTISTA, J. Preparation of a rice bran enzymatic extract with potential use as functional food. Food Chemistry, v.98, p.742-748, 2006.

40 PRIEFERT, H.; RABENHORST, J.; STEINBUCHEL, A. Biotechnological production of vanillin. Appl. Microbiol. Biotechnol., v.56, p.296-314,2001.

41 QURESHI, A.A.; QURESHI, N; WRIGHT, J.J.K.; SHEN, Z.; KRAMER, A.; GAPOR, A. Lowering of serum cholesterol in hypercholesterolemic humans by tocotrienols (palmvitee). Am. J. Clin. Nutr., v.53, p.1021-1026, 1991.

42 RODRIGUES, C. E. C.; ONOYAMA M. M.; MEIRELLES, A.J.A. Optimization of the rice bran oil deacidification process by liquid-liquid extraction. Journal of Food Engineering, v.73, n. 4, p. 370-378, 2006.

43 RODRIGUES, C.E.C.; PESSÔA FILHO P. A.; MEIRELLES, A.J.A. Phase equilibrium for the system rice bran oil + fatty acids + ethanol + water $+\gamma$-oryzanol + tocols. Fluid Phase Equilibria, v.216, p.271-283, 2004.

44 SARAVANAN, M. M.; BHOSLE, B.M.; SUBRAMANIAN, R. Processing hexane-oil micelle using a nonporous polymeric composite membrane. Journal of Food Engineering, v.74, p.529-535, 2006.

SAUNDERS, R.M. The properties of rice bran as a foodstuff. Cereal Foods World, St. Paul, v.35, n.7, p.632-636, 1990.

SAYRE, B.; SAUNDERS, R. Rice bran and rice bran oil. Lipid Technol., v. 2, p.72-76, 1990.

47 SHIN, T. S.; GODBER, J.S.; MARTIN, D. E.; WELLS, J. H. Hydrolytic stability and changes in E vitamers and oryzanol of extruded rice bran during storage. Journal of Food Science, n.62, p. 704-708, 1997.

48 SHOPOVA, N.; MILKOVA, T. Thermal decomposition of cholesteryl esters of cynnamic acid derivatives and their effect on the alphatetralylhydroperoxyde free-radical-induced decomposition. Thermochimica Acta, v.356, p.101$107,2000$.

49 SILVA, M.A.da; SANCHES, C.; AMANTE, E.R. Farelo de arroz composição e propriedades. Óleos \& Grãos, v. 10, n. 61, p. 34-42, 2001.

50 SILVA, M.A. da; SANCHES, C.; AMANTE, E.R. Prevention of hydrolytic rancidity in rice bran. Journal of Food Engineering, v.75, n.4, p.487-491, 2006.

51 TANG, S.; HETTIARACHCHY, N. S.; HORAX, R.; ESWARANANDAM, S. Physicochemical properties and functionality of rice bran protein hydrolyzate prepared from heat-stabilized defatted rice bran with the aid of enzymes. Journal of Food Science, v.68, p.152-157, 2003.

52 WANG, M.; HETTIARACHCHY, N. S.; QI, M.; BURKS, W.; SIEBENMOGEN, T. Preparation and functional properties of rice bran protein isolate. Journal of Agricultural and Food Chemistry, v.47, p.411-416, 1999.

53 WILSON, T.A.; AUSMAN, L.M.; LAWTON, C.W.; HEGSTED, D.M.; NICOLOSI, R.J. Comparative cholesterol lowering properties of vegetable oils: beyond fatty acid. Journal American Coll. Nutr., n.19, p. 601-607,2000.

54 WILSON, T.A.; NICOLOSIA, R.J.; WOOLFREYA, B.; KRITCHEVSKYB, D. Rice bran oil and oryzanol reduce plasma lipid and lipoprotein cholesterol concentrations and aortic cholesterol ester accumulation to a greater extent than ferulic acid in hypercholesterolemic hamsters. Journal of Nutritional Biochemistry, v.18, p.105-112, 2007.

$55 \mathrm{XU}$, Z.M.; GODBER, J.S. Comparison of supercritical fluid and solvent extraction methods in extracting gammaoryzanol from rice bran, J. Am. Oil Chem. Soc., v.77, n.5, p.547-551, 2000.

$56 \mathrm{XU}$, Z.; HUA, N.; GODBER, J. S. Antioxidant activity of tocopherols, tocotrienols, and gamma-oryzanol components from rice bran against cholesterol oxidation accelerated by 2,2'-azobis (2-methylpropionamidine) dihydrochloide. Journal Agric. Food Chem., v.49, p.2077-2081, 2001.

57 ZAMBIAZI, R. The role of endogenous lipid components on vegetable oil stability. Manitoba/Canadá, 1997. $304 \mathrm{f}$. Thesis (Doctor of Philosophy), Food and Nutritional Sciences Interdepartmental Program, University of Manitoba.

58 ZHENG, L.; ZHENG, P.; SUN, Z.; BAI, Y.; WANG, J.; GUO, X. Production of vanillin from waste residue of rice bran oil by Aspergillus niger and Pycnoporus cinnabarinus. Bioresource Technology, v.98, p.1115-1119, 2007. 